\title{
Effect of acidic fluoride solution on the corrosion resistance of ZrTi alloys for dental implant application
}

\author{
D. Mareci ${ }^{1}$, G. Bolat ${ }^{1}$, A. Cailean ${ }^{1}$, J.J. Santana ${ }^{2}$, J. Izquierdo ${ }^{3}$, and R.M. Souto ${ }^{3,4}$ \\ 1 “Gheorghe Asachi” Technical University of Iasi, Faculty of Chemical Engineering and Environmental \\ Protection, 73 Prof. Dr. Doc. D. Mangeron St., 700050, Iasi, Romania \\ ${ }^{2}$ Department of Process Engineering, University of Las Palmas de Gran Canaria, Campus Universitario \\ de Tafira, 35017 Las Palmas de Gran Canaria (Gran Canaria, Canary Islands), Spain. \\ ${ }^{3}$ Department of Chemistry, University of La Laguna, 38200 La Laguna (Tenerife, Canary Islands), \\ Spain \\ ${ }^{4}$ Instituto Universitario de Materiales y Nanotecnologías, University of La Laguna, 38200 La Laguna \\ (Tenerife, Canary Islands), Spain
}

\begin{abstract}
The electrochemical behavior of Zr5Ti, Zr25Ti, and Zr45Ti, with and without surface modification were monitored in acidic artificial saliva $(\mathrm{pH}=3)$ containing $\mathrm{NaF}$ concentrations 0.2 , 0.5, and 1 wt.\%, simulating the fluoride concentrations in dental rinses. A passive behaviour for thermally oxidized ZrTi alloys was found using EIS, and XPS data show that the protective oxide film contains both $\mathrm{TiO}_{2}$ and $\mathrm{ZrO}_{2}$, though titanium contents in the outer layer bigger than those in the base alloy result from thermal oxidation. High corrosion resistance to acidic fluoridated environments of ZrTi alloys treated using thermal oxidation in air at $500{ }^{\circ} \mathrm{C}$.
\end{abstract}

Keywords: Titanium; Zirconium; EIS; XPS; Passive films. 


\section{Introduction}

Zirconium and titanium exhibit a high corrosion resistance in severely corrosive environments, particularly those of oxidizing nature or containing chlorides or fluorides. Next, the inertness of zirconium and titanium and their alloys when inserted in the human body makes them suitable candidate materials for biomedical application such as either surgical instruments or bone and dental implants [1]. The beneficial effect of surface topography on osseointegration, achieved through reducing techniques such as grit-blasting, sandblasting and acid-etching, has been the topic of investigation for several decades. Today micro-roughened surfaces dominate the market as they have been shown to achieve faster bone integration, a higher percentage of bone to implant contact and a greater resistance to shear, as determined by removal torque values, when compared with titanium implants with a polished or machined surface [2].

In searching new alloys with improved mechanical strength, it would be optimal if one could also conserve the micro-roughened topography and hydrophilic surface properties that have proven to be integral to the success of commercially pure titanium (cp Ti) implants. In this respect, the binary zirconium-titanium (ZrTi) alloys stand apart from any of the $\alpha-\beta$ microstructured alloys because they maintain the same $\alpha$ structure as cp Ti. These metals spontaneously passivate by forming thin oxide films on their surface both in air and in electrolytes at open circuit, though pure $\mathrm{Zr}$ is susceptible to localized corrosion by chloride ions [3]. Though corrosion resistance can be improved by alloying $\mathrm{Zr}$ with Ti, still localized corrosion may occur depending on the Ti/Zr ratio [4-7], and surface modification techniques are currently investigated to achieve improved corrosion resistance (namely electrochemical anodization [8-12], micro-arc oxidation (MAO) [12], and thermal oxidation [13]). From a biomedical standpoint, it has been shown that bone implant contact is higher in the case of Zr compared to Ti [14], whereas cytotoxicity is lower for $\mathrm{ZrO}_{2}$ than for $\mathrm{TiO}_{2}$ rutile [15-17]. In particular, the equiatomic ZrTi alloy exhibits excellent mechanical properties, with hardness and tensile strength values about two-anda-half times higher than those shown by pure Zr and $\mathrm{Ti}$ [18]. As a result, the ZrTi alloy can be considered an attractive implant material, particularly for use in implant applications of small diameter employed in endossesous dental implants, owing to its improved strength, while maintaining the biocompatibility and osseointegration properties observed for cp Ti [19]. These properties of ZrTi alloys are particularly relevant in relation to the replacement for cp titanium and Ti6Al4V alloy dental implants because the protectiveness of titanium oxide layers is destroyed by fluoride ions when the $\mathrm{NaF}$ 
concentration exceeds 0.1 wt.\% [20,21]. Indeed, a commercial binary TiZr alloy (13-17 wt.\% Zr) is already available in the market under the name Roxolid ${ }^{\circledR}$ [22].

In recent years there has been an increase in the utilization of fluoridated toothpastes, prophylactic gels, and dental rinses to prevent caries formation. The presence of fluoride ions in the mouthwash solutions brings with it aggressiveness in the attack on dental alloys. The commercially available fluoridated products contain high contents of fluoride ions, up to $0.1 \mathrm{wt} . \%$, with $\mathrm{pH}$ values ranging between 7.2 and 3.2 [23]. Additionally, many commercially available fluoridated gels contain even higher concentrations of fluoride ions, up to 1 wt.\%, whereas $\mathrm{pH}$ ranges between 7.2 and 3.2 $[23,24]$. The conscientious health-care provider needs to know the consequences of the effect of fluoride ions on dental metallic materials. Some authors [4,24-29] have found that fluoride ions affect the corrosion behaviour of titanium and its alloys. According to Al-Mayouf et al. [30], the severity of the attack depends on both the concentration of fluoride ions and $\mathrm{pH}$.

The primary goal of this study was to investigate the in vitro effect of acidic fluoride simulated physiological solutions on the corrosion resistance ZrTi alloys. The second objective was to characterize the influence of surface passivation treatment towards the formation of the passive layer on their corrosion behaviour. Thermal oxidation in air at $500{ }^{\circ} \mathrm{C}$ was reported to produce ZrTi materials with enhanced corrosion resistance in Ringer's solution at $37^{\circ} \mathrm{C}$ [13]. In order to characterize the chemical properties of both non-treated and thermally-modified samples, scanning electrochemical microscopy combined with X-ray photoelectron spectroscopy were used. These combined studies allowed relationships between the electrochemical behaviour in artificial physiological environment and the characteristics of the surface to be established.

\section{Materials and methods}

\subsection{Materials}

Three ZrTi alloys have been synthesized by electron beam melting method. The chemical compositions (wt.\%) of experimental alloys are as follows: Zr-4.3\%Ti-0.3\%Nb-0.3\%Mo (named Zr5Ti), Zr-23.8\%Ti-0.4Nb\%Zr-0.7\%Mo (named Zr25Ti), and Zr-43.9\%Ti-0.4\%Nb-0.5\%Mo (named Zr45Ti). The melting procedure was repeated three times in order to obtain chemically homogenized alloys. The chemical compositions have been determined by EDX analysis using a scanning electron microscope Quanta 3D (model AL99/D8229) equipped with EDX detector. The above mentioned percentages of alloying elements have been calculated as averages of ten values. The alloy specimens were cut into 
disks of $0.28 \mathrm{~cm}^{2}$ surface, and they were ground with SiC abrasive paper up to 4000 grit, followed by polishing with $1 \mu \mathrm{m}$ alumina suspension. The samples were next degreased with ethyl alcohol, followed by ultrasonic cleaning with deionised water, and finally dried under air stream. The oxidized samples involved heat-treatment in air at $500{ }^{\circ} \mathrm{C}$ for 2 hours [13]. Both as cast (untreated), and oxidized samples of the ZrTi alloys were considered.

Fusayama artificial saliva was used as test environment for electrochemical characterization. It consisted of $0.400 \mathrm{~g} \mathrm{NaCl}, 0.400 \mathrm{~g} \mathrm{KCl}, 0.795 \mathrm{~g} \mathrm{CaCl}_{2} \cdot 2 \mathrm{H}_{2} \mathrm{O}, 0.780 \mathrm{~g} \mathrm{NaH} \mathrm{PO}_{4} \cdot 2 \mathrm{H}_{2} \mathrm{O}, 0.005 \mathrm{~g}$ $\mathrm{Na}_{2} \mathrm{~S} \cdot 9 \mathrm{H}_{2} \mathrm{O}, 1.000 \mathrm{~g} \mathrm{NH}_{2} \mathrm{CONH}_{2}$, and distilled water up to $1000 \mathrm{~mL}$. Different NaF concentrations (0.2, 0.5 and, 1 wt.\%) were added to the artificial saliva, which simulated the fluoride concentration typically found in fluoridated gels. Acidified artificial saliva was prepared by adding lactic acid to the three fluoridated Fusayama solutions until reaching a $\mathrm{pH}$ value of $3.0 \pm 0.1$.

\subsection{Electrochemical setup}

The alloy specimens were placed in a glass corrosion cell, which was filled with acidified artificial saliva containing chosen amounts of fluoride ions. A saturated calomel electrode (SCE) was used as the reference electrode, and a platinum coil as the counter electrode. The temperature of the electrochemical cell was fixed at $37 \pm 1^{\circ} \mathrm{C}$.

Electrochemical measurements were performed using a potentiostat manufactured by PAR (Model PARSTAT 4000, Princeton Applied Research, NJ, USA). The instrument was controlled by a personal computer and specific software (VersaStudio, PAR, USA). Electrochemical impedance spectra (EIS) were measured prior to conducting the potentiodynamic polarization tests on the samples. The spectra were obtained 1 hour after the electrode was immersed in the acidified artificial saliva solution with different $\mathrm{NaF}$ concentration. An alternating (AC) potential signal of amplitude $\pm 10 \mathrm{mV}$ was used with frequencies in the range of $100 \mathrm{kHz}$ to $1 \mathrm{mHz}$. The EIS experimental data were analyzed in terms of equivalent circuits (EC) using ZSimpWin 3.22 software.

Potentiodynamic measurements were also carried out in acidified artificial saliva with different NaF concentration at $37^{\circ} \mathrm{C}$ using the same electrochemical instrumentation. These measurements were conducted by increasing the potential from -1.0 to $+1.0 \mathrm{VsCE}$, using a scanning rate of $1 \mathrm{mV} \mathrm{s}^{-1}$. Using the dedicated CorrWare software of electrochemical test system, zero current potential ( $E_{\text {corr }}$ ), and the corrosion current density $\left(j_{\text {corr}}\right)$, were determined by Tafel analysis of both anodic and cathodic branches 
of the polarization curves for a range of $\pm 150 \mathrm{mV}$ around the open circuit potential. From the measured potentiodynamic polarization curves, the passive current density $(j$ pass $)$ values were determined too.

All the electrochemical experiments were performed three times. These replications were not sufficient to carry out statistical analysis, but served to verify the reproducibility of the measured data.

\subsection{Morphological and surface analytical measurements}

In order to observe the possible occurrence of surface effects arising from corrosion during immersion in acidic fluoridated artificial saliva, samples were retrieved after completing the electrochemical tests, and they were observed by SEM microscopy. A scanning electron microscope Quanta 3D (model AL99/D8229) was employed.

X-ray photoelectron spectroscopy (XPS) was performed with an ESCALAB 250 spectrometer equipped with dual aluminum-magnesium anodes, using a monochromatized Al K $\alpha$ X-ray radiation (hv $1486.6 \mathrm{eV})$. The spectrometer energy calibration was performed using the $\mathrm{Au} 4 \mathrm{f}_{7 / 2}$ and $\mathrm{Cu} 2 \mathrm{p} 3 / 2$ photoelectron lines. For consistency, all binding energies are reported with reference to the binding energy of the $\mathrm{C} 1$ s core level spectrum corresponding to the carbon contamination layer at $284.6 \mathrm{eV}$.

\section{Results}

\subsection{Electrochemical behaviour}

Electrochemical impedance spectroscopy (EIS) was employed to characterize the corrosion resistance of the protecting oxide films developed on the surface of the ZrTi alloys during thermal oxidation treatment at $500{ }^{\circ} \mathrm{C}$ in air for 2 hours. Experimental samples were introduced in the selected acidified fluoridated artificial saliva at $37^{\circ} \mathrm{C}$ for 1 hour without application of any electric perturbation

to attain their spontaneously-developed open circuit condition ( $\left.E_{\text {corr }}\right)$. Figure 1 shows the electrochemical impedance spectra for the three thermally-oxidized ZrTi alloys at $E_{\text {corr }}$ represented as Bode plots (i.e., plots of the logarithm of the impedance modulus and of the phase angle as a function of the logarithm of the frequency of the AC potential signal). The advantage of the Bode plot is that the data for all measured frequencies are shown, and that a wide range of impedance values can be displayed in one graph. Two distinct regions are observed in the impedance spectra of the thermallyoxidized ZrTi alloys they correspond to systems exhibiting two time constants as revealed by the presence of two maxima in the Bode-phase diagrams. 
For the sake of comparison, the EIS spectra of the cast (untreated) ZrTi alloys recorded after a 1 hour immersion in the acidic artificial saliva $(\mathrm{pH}=3)$ with $0.5 \mathrm{wt} \% \mathrm{NaF}$ were also recorded, and they are given in Figure 2 plotted as Bode and Nyquist diagrams. In this case, the onset of an inductive behaviour is observed in the low frequency range, as indicated by the measurement of phase angles below 0 degrees in the Bode plots depicted in Figure 2A. This feature occurring in the low frequency range is better observed when the impedance spectra were plotted in Figure 2B as Nyquist diagrams, that is, in terms of the real and imaginary components of the impedance vectors determined at each frequency. In this case, the depressed semicircles present an inductive loop in the low frequency range.

Figure 3 depicts experimental potentiodynamic polarization results measured for the thermallyoxidized ZrTi samples immersed in acidified artificial saliva with different NaF concentrations at $37^{\circ} \mathrm{C}$. All three oxidized ZrTi samples did not show an active region because of the passive oxide layer formed on the surface after the thermal oxidation treatment. For the sake of comparison, potentiodynamic polarization curves measured for the cast ZrTi alloys in the same conditions are shown in Figure 4. It is readily observable than more negative open circuit potentials (occurring at ca. -1.0 VSCE) and passivation currents two orders of magnitude bigger were measured for the cast alloys compared to those in Figure 3 for the alloys after thermal oxidation. Furthermore, the stability range of the passive regime is narrower as the Ti content in the alloys is decreased, as characterized by the observation of a new steady growth of the measured current densities at anodic polarizations more positive than +0.4 Vsce for the Zr5Ti and Zr25Ti alloys. These behaviours indicate that the oxide films on the alloys is more protective when they were treated by thermal oxidation at $500{ }^{\circ} \mathrm{C}$ in air.

\subsection{Surface characterization}

Scanning electron microscopy (SEM) analyses of the Zr-Ti alloy surfaces were carried out on retrieved samples after immersion in the test solutions to characterize the corrosion form and extension. Samples were retrieved after either completing the stabilization period at their corresponding open circuit potential, or after the potentiodynamic polarization scans. The presence of fluoride ions in acidic artificial saliva $\left(\mathrm{pH}=3\right.$ ) was found to be detrimental to the protectiveness of $\mathrm{ZrO}_{2}$ surface film formed on Zr-based materials. Typical SEM micrographs of ZrTi samples after anodic polarization tests in acidic artificial saliva with 1 wt.\% NaF terminated at +1.0 VSCE are shown in Figure 5 for both oxidized (A-C) and cast (D-F) alloys. The inspection of the micrographs shows the occurrence of localized attack at the surface of Zr5Ti and Zr25Ti alloys, and the development of a uniform corrosion process in the 
case of the Zr45Ti alloy. Formation of corrosion products is also observed for the two alloys with smaller Ti contents around the bigger pits developed on their surface. This observation evidenced that the alloy with the higher $\mathrm{Ti}$ content was less susceptible to pitting corrosion when the material was polarized at anodic potentials during exposure to fluoride containing electrolytes. The formation of corrosion pits under anodic polarization up to $+1.0 \mathrm{~V}_{\mathrm{SCE}}$ is a common feature for pure zirconium [31] and $\mathrm{ZrNi}$ alloys [32], and it has also been recently observed for cast ZrTi alloys exposed to aqueous solution containing chloride ions [7]. Indeed, this is again the case for the cast ZrTi alloys exposed to fluoride solution, since pitting corrosion was observed in all cases (cf. Figure 5 D-F). Yet, the cast Zr45Ti alloy showed different corrosion features (Figure 5F) because pits were also seen on its surface but to a much lesser extent that in the case of the other alloys.

Figure 6 shows the micrographs taken from retrieved cast ZrTi alloys after 1 hour immersion times in acidified artificial saliva containing $0.5 \mathrm{wt} \% \mathrm{NaF}$. In this case, the samples were left unpolarized in the environment at their corresponding $E_{\text {corr }}$ values. Surface analysis of ZrTi alloys by SEM indicated significant surface degradation after 1 hour immersion in acidified artificial saliva with 0.5 wt.\% NaF, even though they were not subjected to anodic polarization in the test media. Conversely, no signs of corrosive attack on the exposed surfaces could be observed it samples were retrieved at the open circuit potential, that is, without application of an anodic polarization (not shown in the figure).

The effect of surface treatment was further investigated by XPS, focusing on the chemical composition of the oxide layers formed on the different ZrTi alloys under investigation. Figure 7 shows the XPS survey spectra recorded at the surface of the three ZrTi alloys after thermal oxidation at $500{ }^{\circ} \mathrm{C}$ for 2 hours. The predominant elements detected at the surface of the alloys were $\mathrm{C}$, O, Ti and $\mathrm{Zr}$ are the predominant elements detected for all $\mathrm{Zr} / \mathrm{Ti}$ ratios. Carbon concentration is related to air exposure with the formation of carbon-containing compounds at the outermost surface layer. Signals corresponding to $\mathrm{Nb}$ and Mo metals were not detected this time as they are contained in very small amounts in the samples.

\section{Discussion}

\subsection{Effect of thermal oxidation}

It was obvious that both $\mathrm{Ti}$ and $\mathrm{Zr}$ oxides are present in the protective film formed on the surface of the ZrTi alloys as result of the thermal oxidation treatment in air at $500{ }^{\circ} \mathrm{C}$. The XPS peaks related to Zr metal are located between 182.0 and $184.4 \mathrm{eV}$, for Ti metal between 457.9 and $459.6 \mathrm{eV}$, and for $\mathrm{O}$ 
1s between 535.0 and $530.9 \mathrm{eV}$, similar to reported values for Zr50Ti [31]. To reveal the surface distribution of the metals and oxide species, high-resolution spectra of elements were measured as a function of take-off angles, and they are given in Figures 8 and 9 for $\mathrm{Zr}$ and Ti, respectively. Two spinorbit components, corresponding to $\mathrm{Zr} 3 \mathrm{~d}_{3 / 2}$ and $\mathrm{Zr} 3 \mathrm{~d}_{5 / 2}$, are observed in Figure 8 for zirconium, and the corresponding peak energies after deconvolution of the XPS peaks are given in Table 1. The average separation between the signals is $2.4 \mathrm{eV}$, in good agreement with previous reports on Zr50Ti [33], and for other transition metal alloys subjected to similar thermal oxidation procedures [34]. The values of the binding energies increase with higher titanium contents in the alloy. In this way, the binding energies determined for the outermost oxide layer (given by take off angles of 20²), are $182.0 \mathrm{eV}$ for Zr5Ti, 182.9 $\mathrm{eV}$ in Zr25Ti, and $183.3 \mathrm{eV}$ for Zr45Ti. These values are very close to those reported for $\mathrm{Zr}^{4+} 3 \mathrm{~d}_{5 / 2}$ in $\mathrm{ZrO}_{2}$ for passive layers formed on pure zirconium [35] and its alloys [11,13,36-38]. The weak shift of the peak position towards higher binding energies with increasing $\mathrm{Zr}$ content in the alloy, may be attributed to smaller contribution of Zr metal to the measured signal.

A similar trend between the binding energies and titanium contents in the alloy is also observed in the deconvoluted XPS peaks for Ti 2p3/2 shown in Figure 9. They shift from $458.3 \mathrm{eV}$ in Zr5Ti to $459.5 \mathrm{eV}$ in the alloys with higher Ti contents as for the outermost oxide layer. These values are in good agreement with the reported value of $458.8 \mathrm{eV}$ for $\mathrm{Ti}^{4+} 2 \mathrm{p} 3 / 2$ [34], while the binding energy for $\mathrm{TiO}$ is $453.8 \mathrm{eV}$. Analogously, the binding energy for Ti 2p1/2 in the outermost oxide layer is $466 \mathrm{eV}$ in the alloy with the lowest titanium content, and shifts to $465.0 \mathrm{eV}$ for Zr25Ti and Zr45Ti. As result, the difference in binding energies between $\mathrm{Ti} 2 \mathrm{p}_{3 / 2}$ and $\mathrm{Ti} 2 \mathrm{p} 1 / 2$ signals amounts $5.7 \mathrm{eV}$ in average, a value that supports the occurrence of $\mathrm{Ti}^{4+}$ state as $\mathrm{TiO}_{2}$ in the surface films, in accordance to previous reports [33]. Higher contents in the ZrTi alloys originates a shift of the binding energies of the Ti 2p signals to higher values, progressively approaching the typical values for $\mathrm{TiO}_{2}$ layers developed on pure titanium [34,35], and also for Zr50Ti [33]. Therefore, the oxide layers formed on the Zr25Ti and Zr45Ti alloys are probably composed by mixed Ti-Zr oxides [10,11]. In this respect, the formation of TiZrO4 during the oxidation of equimolar TiZr alloy in air at temperatures between 500 and $800{ }^{\circ} \mathrm{C}$ has been proposed [39].

The distribution of these two metal oxides through the protecting surface films can be analyzed in semi-quantitative terms by comparing the XPS data obtained using different take-off angles. In this way, internal chemical composition can be derived from the measurements taken at $45^{\circ}$ and $80^{\circ}$, and their comparison with those from the outermost layer obtained at $20^{\circ}$. Small take-off angles correlate 
with the outermost surface, whereas bigger take-off angles reveal atom content closer to the interface with the bulk of the material. In this way, depth-profiling over ca. $5 \mathrm{~nm}$ was made. A summary of the data is provided in Table 1. It is found that small enrichment in $\mathrm{ZrO}_{2}$ occurred in the outermost layer for the oxides formed on the ZrTi alloys with the lower titanium contents, namely Zr25Ti and Zr45Ti. The opposite trend occurred for Zr5Ti, as the amount of $\mathrm{ZrO}_{2}$ decreases as we move towards the surface of the material, leading to titanium enrichment. Quantification of $\mathrm{TiO}_{2}$ from the data measured using $80^{\circ}$ take-off angle was only achieved from Zr45Ti, the alloy with highest titanium content. It should also be noticed that the $\mathrm{Zr} / \mathrm{Ti}$ ratios in the thermally-formed oxide layers are close to those in the bulk alloy for Zr25Ti and Zr45Ti, but they increase at the outermost surface. That is, there is less titanium in the outermost layer of the surface oxide than in the bulk of the material.

\subsection{Electrochemical stability of protecting oxide layers in acidic fluoridated media}

Though the polarization curves shown in Figure 3 indicate that the oxide layers formed on the surface of the three ZrTi alloys during the thermal oxidation treatment confer some degree of passivation to these materials immersed in acidic fluoride artificial saliva, differences between these materials can be observed in their electrochemical behaviour as a function of fluoride ion concentration. In fact, the polarization curves revealed a narrow active range at small anodic polarization, and thus values of the corrosion potentials ( $\left.E_{\text {corr }}\right)$, and the corrosion current densities $(j$ corr), were determined by Tafel analysis of both the anodic and the cathodic branches in the polarization plots. The average values of $E_{\text {corr }}$ and $j$ corr determined from the polarization curves are presented in Table 2. Though the corrosion current densities determined by this extrapolation method may not be fully accurate due to some degree of distortion related to oxide formation on the surface of the alloys, the values given in Table 2 may be used to provide a relative ranking of the corrosion resistance in artificial saliva solutions containing different fluoride concentration [29,40]. From these data it is possible to observe low values of corrosion rate for the three alloys in the fluoride solution with the lower concentration, and even rather low for Zr5Ti in artificial saliva containing $1 \mathrm{wt} . \% \mathrm{NaF}$.

The effect of increasing fluoride ion contents on the three materials is observed as the combination of less noble open circuit potential values and higher current densities related to metal dissolution even through the passivating oxide surface layers, though Zr5Ti presents always the slowest corrosion rates in these fluoride-containing environments. Regarding the potential plateau related to the passive regime, Zr5Ti also presents the smallest passivating currents, and show no evidence of a current 
increase related to breakdown of the passive film for potential excursions up to $+1.0 \mathrm{~V}_{\text {SCE}}$, a value significantly higher than any reported in the human body [41]. This feature suggests that the oxide film formed on the surface of Zr5Ti is more blocking regarding electrolytic conductivity. On the basis of potentiodynamic polarization data, thermally-oxidized Zr5Ti can be regarded to be the more corrosion resistant material for biomaterial application in fluoride-containing environments. It must be noticed that the opposite trend regarding corrosion resistance with increasing Ti content in the ZrTi alloys occurred when they were exposed to chloride-containing environments instead [13]. These observations can be related to the poor resistance of $\mathrm{TiO}_{2}$ in the presence of fluoride ions, due to the formation of a Ti-F complex compound $\left(\mathrm{Na}_{2} \mathrm{TiF}_{6}\right)$ on the surface [42] of the ZrTi alloys with greater Ti content (i.e., Zr25Ti and Zr45Ti). But in both cases, a major improvement in corrosion resistance was produced after thermal oxidation at $500{ }^{\circ} \mathrm{C}$ compared to the behaviour of the cast alloys (cf. Figures 3 and 4 for fluoridecontaining solutions, and Figure 1 in ref. [7] and Figure 1 in ref. [13] in the case of chloride-containing electrolytes).

SEM micrographs of retrieved samples show evidences of localized corrosive attack on their surfaces after polarization up to $+1.0 \mathrm{VSCE}$ in the artificial saliva containing the highest fluoride concentration considered (i.e., 1 wt.\% NaF). Yet it is remarkable to compare the micrographs of the treated alloys shown in Figure 5 with those of untreated samples obtained after immersion for 1 hour in a significantly less concentrated fluoride solution of $0.5 \mathrm{wt} \%$, even though no anodic polarization was applied to them (cf. Figure 6). A more extended corroding attack has been thus observed for the untreated samples even though no anodic polarization was applied to the samples, in addition to less fluoride content in the artificial saliva compared to the conditions experienced by the oxidized samples imaged in Figure 5.

Zr corrodes in acidic $(\mathrm{pH}<3.5)$ solutions, and the range of oxide stability extends between $\mathrm{pH}$ 3.5 and 13 [43]. If passivation does not occur, Zr will react violently with chemical species such as chloride that are present in the environment, and the metal will be transformed into its ionic state [44]. Therefore, it is reasonable to expect that the presence of fluoride ions in artificial saliva at $\mathrm{pH}=3$ effectively promotes dissolution of the protective oxide films developed on these materials, such attack being more vigorous for the cast ZrTi alloys than for the thermally-oxidized ones. At this point, some concern may arise regarding the use of glass vessels with fluoride solutions, as they are often employed in the electrochemical characterization of metallic biomaterials in fluoridated artificial solutions $[6,23,45]$. It is well established that fluoride causes corrosion of silicate glasses as this anion complexes 
with Si(IV). This feature cannot be ignored in the present work, and data obtained in artificial saliva containing 1 wt.\% NaF may have been influenced to some extent as they have been taken after 1 hour stabilization in the electrolyte. Yet, it is important to notice that degradation of cast ZrTi alloys was readily observable after only $10 \mathrm{~min}$ exposure to acidified artificial saliva $(\mathrm{pH}=3.4)$ containing only 0.05 wt.\% NaF [6]. Anyway, the use of glass cells must be avoided in future investigations on the effect of fluoride ions on the electrochemical behaviour of materials.

The protecting nature of the oxide films developed on the treated ZrTi alloys is further demonstrated by the observation of two relaxation time constants in the impedance spectra given in Figure 1. They correspond to the barrier characteristics of the oxide film towards electrolyte penetration that dominates the impedance response in the low-frequency range, and to the charge transfer process in the surface of the alloys at higher frequencies. This is the typical response of an inhomogeneous surface film, which consists of a compact inner layer and a more porous outer layer [46]. Such duplex structure of the oxide film has been typically reported for pure titanium $[47,48]$ and titanium alloys $[7,12,13,48$ 53] in many electrolytic environments.

Analysis of these spectra in terms of an equivalent circuit (EC) allowed the values of the relevant impedance parameters to be derived, which supply quantitative information concerning the experimental system. The EC employed to model the system parameters is depicted in Figure 10A, and the fitted parameters are given in Table 3. The model consists of a series combination of the solution resistance of the test electrolyte, $R_{\text {sol, }}$ and two parallel constant phase elements/resistor pairs, $Q_{1} / R_{1}$ and $Q_{2} / R_{2}$, where subscripts 1 and 2 designate the low and high frequency time constants, respectively. $R_{1}$ designates the additional resistance of the solution inside the pores in the outer oxide layer, $C_{1}$ corresponds to the capacitance of the pore wall, whereas $R_{2}$ and $C_{2}$ give the resistance and the capacitance of the inner barrier layer. Constant phase elements $(\mathrm{CPE}, Q)$ were used in the EC instead of capacitors to account for the effects of deviations to ideal dielectric behaviour arising form electrode roughness and heterogeneities of the surface films [54]. The impedance of a CPE is defined as:

$$
Z_{(C P E)}=\frac{1}{Y_{0}(j \omega)^{n}}
$$

where $\omega$ is the angular frequency and $Y_{0}$ is a constant, and the value of the exponent $n$, ranging $-1 \leq n \leq$ 1 , indicates the deviation from ideal capacitive behaviour (e.g., when $n \approx 1$ ). A very good correlation was obtained between EIS data using the proposed equivalent circuit and the experimental impedance spectra, and the fitting quality of the experimental EIS spectra to the model was established from the 
chi-squared $\left(\chi^{2}\right)$ values, in the order of $10^{-4}$. The values of fitted parameters of the EC and corresponding fit qualities are listed in Table 3.

The Bode-magnitude plots in Figure 1 show that impedance decreased with the increase in the concentration of $\mathrm{NaF}$ added to the acidified artificial saliva for the three oxidized ZrTi alloys. However, it can be seen in Table 3 that the resistance of the oxide layer present in the surface of the Zr5Ti alloy is higher than those on Zr25Ti and Zr45Ti alloys. High values of $R_{2}$ (in the order of $10^{6} \Omega \mathrm{cm}^{2}$ ) are observed at $E_{\text {corr }}$ in all cases. Additionally, it must be noticed that the values of $R_{2}$ are significantly higher (by ca. three orders of magnitude) than those determined for $R_{1}$ (cf. Table 3). This indicates that the corrosion resistance of the oxidized ZrTi alloys in acidified fluoridated artificial saliva arises mainly from the compact passive oxide film formed on the surface of the materials.

Estimates regarding the thicknesses of the compact inner oxide layers present on the thermallyoxidized ZrTi alloys can be made by assuming a homogenous composition of the film. Then, by considering the film to act as a parallel plate dielectric, the capacitance will be related to the thickness according to:

$$
C=\frac{\varepsilon \varepsilon_{0} A}{d}
$$

where $\varepsilon$ is the dielectric constant of the oxide, $\varepsilon_{0}$ the vacuum permittivity, $A$ the geometric area, and $d$ is the thickness. Higher values of capacitance correspond to smaller thicknesses. Capacitance values can be extracted from the constant phase element $Q_{2}$ using [55]:

$$
C=\left(R^{1-n} Q\right)^{1 / n}
$$

To that end, the $\mathrm{Zr} / \mathrm{Ti}$ ratio in the metal matrix was assumed to hold also in the oxide layer, using $\varepsilon=22$ for $\mathrm{ZrO}_{2}$ [56], and $\varepsilon=114$ for $\mathrm{TiO}_{2}$ [57,58]. An additional approximation was to adopt a unity surface roughness factor. The capacitance values of the inner oxide film employed in the calculation, and the thicknesses of the oxide films present on thermal oxidized ZrTi alloys at their open circuit conditions attained in the different test electrolytes are listed in Table 4 . Though these values can only be regarded as an estimation based on simple assumptions, they support that the oxide layers formed on the surface of the alloys amount only a few nanometers. This feature is important as to confirm the validity of the surface characterization procedure based on XPS data given in Section 4.1, for the oxide layers under consideration are thinner than the penetration-depth of angle-resolved XPS. The values reported here are in the same order than those determined using surface characterization techniques for pure titanium [59,60], pure zirconium [61], and Zr-based alloys [5,62]. On the basis of the estimated thicknesses for 
the innermost oxide layer formed on the ZrTi alloys in the fluoridated solutions given in Table 4, the thickest oxide layer is observed on Zr5Ti (ca. $1.39 \mathrm{~nm})$.

Major corrosion occurred when the untreated ZrTi alloys were exposed to the fluoride-containing solutions instead. Smaller impedance values were measured at all frequencies of the applied AC signal, together with the observation of an inductive behaviour of the system in the low frequency range of the Nyquist diagrams in Figure 3. In this case, a different EC had to be employed to describe the impedance characteristics of the untreated alloys in acidified fluoridated solution that would take in account the occurrence of an inductive response. The corresponding EC is given in Figure 10B, and the corresponding impedance parameters are listed in Table 5. $R_{1}$ represents the charge transfer resistance, one order magnitude smaller than for the thermally-oxidized samples, and indication of the low electrochemical stability of the cast ZrTi alloys in the fluoride-containing solution. The constant phase element $Q_{1}$ corresponds to the double layer as evidenced by the high values of the $n_{1}$ exponent. The occurrence of the inductive combination $R_{2} L$ is attributed to the relaxation of the corrosion products formed on the electrode surface during degradation of the material in the environment [63]. In fact, a major decrease in the corrosion resistance of the materials is revealed by the very low values of the charge transfer resistance $R_{1}$, amounting approximately $10^{2} \Omega \mathrm{cm}^{2}$, a finding that reveals the dissolution of the biomaterial in this electrolytic environment. Therefore, the oxide layer spontaneously formed in air at ambient temperature on the ZrTi alloys is less resistant as the Ti content in the alloys increases [64], and cannot protect these materials from corrosion in fluoride-containing environments, contrary to the good protection characteristics shown in fluoride-free artificial physiological solution [7].

\section{Conclusions}

1. Acidic fluoridated saliva is a very aggressive environment for dental materials that can be satisfactorily faced by ZrTi alloys subjected to thermal oxidation treatments.

2. Electrochemical data show that the corrosion stability of ZrTi alloys is greatly affected by the presence of fluoride ions in acidic artificial saliva, though it can be significantly improved by employing surface preparation methods.

3. Thermal oxidation in air at $500{ }^{\circ} \mathrm{C}$ for 2 hours leads to the formation of passivating oxide layers that more efficiently outstand the aggressive effect of fluoride ions in concentrations similar to those used in dental rinses, though making these materials adequate for the manufacturing of implants. 
4. The occurrence of a passivity regime for the thermally oxidized ZrTi alloys immersed in acidic fluoride artificial saliva was established from potentiodynamic polarization and EIS measurements.

5. Protective oxides formed on the surface of the alloys alter surface preparation contain mixtures of $\mathrm{TiO}_{2}$ and $\mathrm{ZrO}_{2}$, with enrichment of the former in the outermost layer. Though $\mathrm{TiO}_{2}$ could not be detected in the innermost oxide layer for $\mathrm{Zr} 5 \mathrm{Ti}$, the amount of $\mathrm{TiO}_{2}$ increases at the expense of $\mathrm{ZrO}_{2}$ as we move towards the outermost surface of the material, as it occurs also in the alloys with higher titanium content.

6. The overall $\mathrm{Zr} / \mathrm{Ti}$ ratios in the protective surface layers are smaller than those employed in the manufacturing of the alloys.

\section{Acknowledgments}

This work was supported by Romanian National Authority for Scientific Research (CNCSUEFISCDI, project No. PN-II-ID-PCE-2011-3-0218), and by the Spanish Ministry of Economy and Competitiveness (MINECO, Madrid, Spain) and the European Regional Development Fund (prject No. CTQ2012-36787). A Research Training Grant awarded to J.I. by the Spanish Ministry of Science and Innovation (Programa de Formación de Personal Investigador) is appreciated. The use of General Research Services at the University of La Laguna (SEGAI-ULL) is acknowledged. Thanks are due to Zirom S.A. (Giurgiu, Romania) for kindly providing the ZrTi alloys used in this work.

\section{References}

1. M. Pourbaix, Electrochemical corrosion of metallic biomaterials, Biomaterials 5 (1984) 122-134.

2. D. Buser, Titanium for dental application (II): Implants with roughened surfaces. In: Titanium in Medicine (D. Brunette, P. Tengvall, M. Textor, P. Thomson, editors). Springer, Berlin, 2001, p 875888.

3. M.M. Lohrengel, Formation of ionic space charge layers in oxide films on valve metals, Electrochimica Acta 39 (1994) 1265-1271.

4. N.T.C. Oliveira, S.R. Biaggio, R.C. Rocha-Filho, N. Bocchi, Electrochemical studies on zirconium and its biocompatible alloys $\mathrm{Ti}-50 \mathrm{Zr}$ at.\% and $\mathrm{Zr}-2.5 \mathrm{Nb}$ wt.\% in simulated physiologic media, Journal of Biomedical Materials Research A 74 (2005) 397-407. 
5. N.T.C. Oliveira, E.A. Ferreira, L.T. Duarte, S.R. Biaggio, R.C. Rocha-Filho, N. Bocchi, Corrosion resistance of anodic oxides on the Ti-50Zr and Ti13Nb-13Zr alloys, Electrochimica Acta 51 (2006) 2068-2075.

6. D. Mareci, D. Sutiman, R. Chelariu, F. Leon, S. Curteanu, Evaluation of the corrosion resistance of new ZrTi alloys by experiment and simulation with an adaptive instance-based regression model, Corrosion Science 73 (2013) 106-122.

7. G. Bolat, J. Izquierdo, J.J. Santana, D. Mareci, R.M. Souto, Electrochemical characterization of ZrTi alloys for biomedical applications, Electrochimica Acta 88 (2013) 447-456.

8. N.T.C. Oliveira, S.R. Biaggio, R.C. Rocha-Filho, N. Bocchi, Studies on the stability of anodic oxides on zirconium biocompatible alloys, Journal of the Brazilian Chemical Society 13 (2002) 463-468.

9. H. Habazaki, M. Uozumi, H. Konno, K. Shimizu, S. Nagata, K. Asami, K. Matsumoto, K. Takayama, Y. Oda, P. Skeldon, G.E. Thompson, Influences of structure and composition on growth of anodic oxide films on Ti-Zr alloys, Electrochimica Acta 48 (2003) 3257-3266.

10. M. Santamaria, F. Di Quarto, H. Habazaki, Photocurrent spectroscopy applied to the characterization of passive films on sputter-deposited Ti-Zr alloys, Corrosion Science 50 (2008) 2012-2020.

11. E.A. Ferreira, R.C. Rocha-Filho, S.R. Biaggio, N. Bocchi, Corrosion resistance of the Ti-50Zr at.\% alloy after anodization in different acidic electrolytes, Corrosion Science 52 (2010) 4058-4063.

12. L.T. Duarte, S.R. Biaggio, R.C. Rocha-Filho, N. Bocchi, Surface characterization of oxides grown on the Ti-13Nb-13Zr alloy and their corrosion protection, Corrosion Science 72 (2013) 35-40.

13. G. Bolat, J. Izquierdo, D. Mareci, D. Sutiman, R.M. Souto, Electrochemical characterization of ZrTi alloys for biomedical applications. Part 2: The effect of thermal oxidation, Electrochimica Acta 106 (2013) 432-439.

14. N. Saulacic, D.D. Bosshart, M.M. Bornstein, S. Berner, D. Buser, Bone apposition to a titaniumzirconium alloy implant as compared to two other titanium-containing implants, European Cells Materials 23 (2012) 273-288.

15. M.B. Guglielmotti, S. Renou, R.L. Cabrini, A histomorphometric study of tissue interface by laminar implant test in rats, International Journal of Oral and Maxillofacial Implantology 14 (1999) 565-570. 
16. Y. Ikarashi, K. Toyoda, E. Kobayashi, H. Doi, T. Yoneyama, H. Hamanaka, T. Tsuchiya, Improved biocompatibility of titanium-zirconium (Ti-Zr) alloy: tissue reaction and sensitization to Ti-Zr alloy compared with pure Ti and Zr in rat implantation study, Materials Transactions 46 (2005) 22602267.

17. S. Sista, C. Wen, P.D. Hodgson, G. Pande, The influence of surface energy of titanium-zirconium alloy on osteoblast cell functions in vitro, Journal of Biomedical Materials Research A 97 (2011) 27-36.

18. E. Kobayashi, S. Matsumoto, T. Yoneyama, H. Hamanaka, Mechanical properties of the binary titanium-zirconium alloys and their potential for biomedical materials, Journal of Biomedical Materials Research 29 (1995) 943-950.

19. H.M. Grandin, S. Berner, M. Dard, A review of titanium zirconium (TiZr) alloys for use in endosseous dental implants, Materials 5 (2012) 1348-1360.

20. H.-H. Huang, Effects of fluoride concentration and elastic tensile strain on the corrosion resistance of commercially pure titanium, Biomaterials 23 (2002) 59-63.

21. H.-H. Huang, Effect of fluoride and albumin concentration on the corrosion behavior of Ti-6Al-4V alloy, Biomaterials 24 (2003) 275-282.

22. N. Bernhard, S. Berner, M. De Wild, M. Wieland, The binary TiZr alloy-A newly developed Ti alloy for use in dental implants, Forum Implantologicum 5 (2009) 30-39.

23. G. Rondelli, B. Vicentini, Localized corrosion behaviour in simulated human body fluids of commercial Ni-Ti orthodontic wires, Biomaterials 20 (1999) 785-792.

24. S. Kumar, T.S.N.S. Narayanan, S.S. Kumar, Influence of fluoride ion on the electrochemical behaviour of $\beta$-Ti alloy for dental application, Corrosion Science 52 (2010) 1721-1727.

25. L. Reclaru, J.M. Meyer, Effects of fluorides on titanium and other dental alloys in dentistry, Biomaterials 19 (1998) 85-92.

26. N. Schiff, B. Grosgogeat, M. Lissac, F. Dalard, Influence of fluoride content and $\mathrm{pH}$ on the corrosion resistance of titanium and its alloys, Biomaterials 23 (2002) 1995-2002. 
27. A.M. Al-Mayouf, A.A. Al-Swayih, N.A. Al-Mobarak, Effect of potential on the corrosion behavior of a new titanium alloy for dental implant applications in fluoride media, Materials and Corrosion 55 (2004) 88-94.

28. T.-H. Lee, C.-C. Wang, T.-K. Huang, L.-K. Chen, M.-Y. Chou, H.-H. Huang, Corrosion resistance of titanium-containing dental orthodontic wires in fluoride-containing artificial saliva, Journal of Alloys and Compounds 488 (2009) 482-489.

29. C. Zhang, S. Zhao, X. Sun, D. Sun, X. Sun, Corrosion of laser-welded NiTi shape memory alloy and stainless steel composite wires with a copper interlayer upon exposure to fluoride and mechanical stress, Corrosion Science 82 (2014) 404-409.

30. A.M. Al-Mayouf, A.A. Al-Swayih, N.A. Al-Mobarak, A.S. Al-Jabab, Corrosion behavior of a new titanium alloy for dental implant applications in fluoride media, Materials Chemistry and Physics 86 (2004) 320-329.

31. B.F. Giannetti, M.S.M. Quintino, T. Rabóczkay, Pitting corrosion and passivation of $\mathrm{Zr} / \mathrm{HCl} 1.0 \mathrm{M}$ electrodes: the effect of the pre-immersion in molibdate solutions. Portugaliae Electrochimica Acta 21 (2003) 213-224.

32. K. Asami, H. Habazaki, K. Hawashima, K. Hashimoto, On the unusual morphology of pitting corrosion of amorphous Ni-Zr alloys, Corrosion Science 34 (1993) 445-459.

33. N.T.C. Oliveira, S.R. Biaggio, P.A.P. Nascente, S. Piazza, C. Sunseri, F. Di Quarto, The effect of thickness on the composition of passive films on a Ti-50Zr at\% alloy, Electrochimica Acta 51 (2006) 3506-3515.

34. L.Z. Zao, S.H. Liu, D.H. Wang, C.H. Pan, XPS studies of oxide films on transition metal, Journal of Electron Spectroscopy 52 (1990) 571-580.

35. C.D. Wagner, W.M. Riggs, L.E. Davies, J.F. Moulder, G.E. Muilenberg, Handbook of X-ray photoelectron spectroscopy, Perkin-Elmer, Eden Prairie, 1979, p. 68-99, 100-101.

36. D.Q. Peng, X.D. Bai, X.W. Chen, Q.G. Zhou, X.Y. Liu, R.H. Yu, Aqueous corrosion behavior of zirconium subjected to high-energy krypton-ion bombardment, Applied Surface Science 227 (2004) 73-80.

37. X.-Y. Li, E. Akiyama, H. Habazaki, A. Kawashima, K. Asami, K. Hashimoto, An XPS study of passive films on corrosion-resistant $\mathrm{Cr}-\mathrm{Zr}$ alloys prepared by sputter deposition, Corrosion Science 39 (1997) 1365-1380. 
38. C. Monticelli, A. Bellosi, M. Dal Colle, Electrochemical behavior of $\mathrm{ZrB}_{2}$ in aqueous solutions, Journal of the Electrochemical Society 151 (2004) B331-B339.

39. I. Halley-Demoulin, C. Valot, D. Ciosmak, M. Lallemant, J.J. Heizmannm C. Laruelle, Oxidation of titanium, zirconium and their alloys, texture of their oxide scales, Materials Science Forum 157-162 (1994) 521-528.

40. E. Poorqasemi, O. Abootalebi, M. Peikari, F. Haqdar, Investigating accuracy of the Tafel extrapolation method in HCl solutions, Corrosion Science 51 (2009) 1043-1054.

41. T.P. Hoar, D.C. Mears, Corrosion-resistant alloys in chloride solutions: materials for surgical implants, Proceedings of the Royal Society London A 294 (1966) 486-510.

42. M.H.O. Könönen, E.T. Lavonius, J.K. Kivilahti, SEM observation on stress corrosion cracking of commercially pure titanium in a topical fluoride solution, Dental Materials 11 (1995) 269-272.

43. D.A. Jones, Principles and prevention of corrosion, 2nd edition. Prentice-Hall, New York, 1996, p. 62-63.

44. C.T. Kwok, P.K. Wong, H.C. Man, F.T. Cheng, Effect of $\mathrm{pH}$ on corrosion behavior of CuCrZr in solution without and with $\mathrm{NaCl}$, Journal of Nuclear Materials 394 (2009) 52-62.

45. N. Schiff, F. Dalard, M. Lissac, L. Morgan, B. Grosgogeat, Corrosion resistance of three orthodontic brackets: a comparative study of three fluoride mouthwashes, European Journal of Orthodontics, 27 (2005) 541-549.

46. F. Mansfeld, Analysis and interpretation of EIS data for metals and alloys, Technical Report 26, Solartron-Schlumberger, Farnborough, 1993, p. 4.1-4.24.

47. J. Pan, D. Thierry, C. Leygraf, Electrochemical impedance spectroscopy study of the passive oxide film on titanium for implant application, Electrochimica Acta 41 (1996) 1143-1153.

48. V.A. Alves, R.Q. Reis, I.C.B. Santos, D.G. Souza, T. De F.Gonçalves, M.A. Pereira-da-Silva, A. Rossi, L.A. da Silva, In situ impedance spectroscopy study of the electrochemical corrosion of $\mathrm{Ti}$ and Ti-6Al-4V in simulated body fluid at $25^{\circ} \mathrm{C}$ and $37^{\circ} \mathrm{C}$, Corrosion Science 51 (2009) 2473-2482.

49. C. Delgado-Alvarado, P.A. Sundaram, Corrosion evaluation of Ti-48Al-2Cr-2Nb (at.\%) in Ringer's solution, Acta Biomaterialia 2 (2006) 701-708.

50. E. Vasilescu, P. Drob, D. Raducanu, I. Cinca, D. Mareci,, J.M. Calderon Moreno, M. Popa, C. Vasilescu, J.C. Mirza Rosca, Effect of thermo-mechanical processing on the corrosion resistance of Ti-6Al-4V alloys in biofluids, Corrosion Science 51 (2009) 2885-2896. 
51. C. Vasilescu, S.I. Drob, E.I. Neacsu, J.C. Mirza Rosca, Surface analysis and corrosion resistance of a new titanium base alloy in simulated body fluids, Corrosion Science 65 (2012) 431-440.

52. G. Bolat, D. Mareci, R. Chelariu, J. Izquierdo, S. González, R.M. Souto, Investigation of the electrochemical behaviour of TiMo alloys in simulated physiological solutions, Electrochimica Acta 113 (2013) 470-480.

53. I. Cvijović-Alagić, Z. Cvijović, J. Bajat, M. Rakin, Composition and processing effects on the electrochemical characteristics of biomedical titanium alloys, Corrosion Science 83 (2014) 245-254.

54. J.A. Bardwell, M.C.H. McKubre, AC impedance spectroscopy of the anodic film on zirconium in neutral solution, Electrochimica Acta 36 (1991) 647-653.

55. J.R. Macdonald, Note on the parameterization of the constant-phase admittance element, Solid State Ionics 13 (1984) 147-149.

56. P.J. Harrop, J.N. Wanklin, The dielectric constant of zirconia, British Journal of Applied Physics 18 (1967) 739-742.

57. L.J. Berberich, M.E. Bell, The dielectric properties of the rutile form of $\mathrm{TiO}_{2}$, Journal of Applied Physics 11 (1940) 681-692.

58. R.A. Parker, Static dielectric constant of rutile ( $\left.\mathrm{TiO}_{2}\right)$, Physical Reviews 124 (1961) 1719-1722.

59. J. Pan, D. Thierry, C. Leygraf, Electrochemical and XPS studies of titanium for biomaterial applications with respect to the effect of hydrogen peroxide, Journal of Biomedical Materials Research 28 (1994) 113-122.

60. M.M. Lohrengel, Formation of ionic space charge layers in oxide films on valve metals, Electrochimica Acta 39 (1994) 1265-1271.

61. P. Meisterjahn, H.W. Hoppe, J.W. Schultze, Electrochemical and XPS measurements on thin oxide films on zirconium, Journal of Electroanalytical Chemistry 217 (1987) 159-185.

62. F. Rosalbino, D. Maccio, P. Giannoni, R. Quarto, A. Saccone, Study of the in vitro corrosion behaviour and biocompatibility of $\mathrm{Zr}-2.5 \mathrm{Nb}$ and $\mathrm{Zr}-1.5 \mathrm{Nb}-1 \mathrm{Ta}$ (at\%) crystalline alloys, Journal of Materials Science: Materials in Medicine 22 (2011) 1293-1302.

63. M. Meticoš-Huković, Z. Pilić, R. Babić, D. Omanović, Influence of alloying elements on the corrosion stability of CoCrMo implant alloy in Hank’s solution, Acta Biomaterialia 2 (2006) 693700. 
64. D. Mareci, G. Bolat, R. Chelariu, D. Sutiman, C. Munteanu, The estimation of corrosion behaviour of ZrTi binary alloys for dental applications using electrochemical techniques, Materials Chemistry and Physics 141 (2013) 362-369.

Table 1. Binding energies and atomic contents obtained by XPS for samples of zirconium and titanium oxides grown in air at $500{ }^{\circ} \mathrm{C}$ for 2 hours.

\begin{tabular}{|c|c|c|c|c|c|c|c|c|c|}
\hline \multirow{2}{*}{\multicolumn{2}{|c|}{ Samples }} & \multicolumn{5}{|c|}{ Binding energies / eV } & \multicolumn{3}{|c|}{ Content / at. \% } \\
\hline & & \multirow{2}{*}{$\begin{array}{c}\text { Ti 2p } 1 / 2 \\
466\end{array}$} & \multirow{2}{*}{$\begin{array}{l}\text { Ti 2p3/2 } \\
458.30\end{array}$} & \multirow{2}{*}{$\begin{array}{c}\mathrm{Zr} \mathrm{3d_{3/2 }} \\
184.3\end{array}$} & \multirow{2}{*}{$\begin{array}{c}\mathrm{Zr} 3 \mathrm{~d}_{5 / 2} \\
182.0\end{array}$} & \multirow{2}{*}{$\frac{\mathrm{O} 1 \mathrm{~s}}{535.0}$} & \multirow{2}{*}{$\begin{array}{c}\mathrm{Ti} \\
1.07\end{array}$} & \multirow{2}{*}{$\frac{\mathrm{Zr}}{12.83}$} & \multirow{2}{*}{$\begin{array}{c}\mathrm{O} \\
36.82\end{array}$} \\
\hline \multirow{3}{*}{ Zr5Ti } & $20^{\circ}$ & & & & & & & & \\
\hline & $45^{\circ}$ & 464.2 & 458.98 & 184.6 & 182.2 & 534.5 & 1.45 & 11.82 & 35.26 \\
\hline & $80^{\circ}$ & - & - & 184.4 & 182.1 & 533.1 & 0 & 10.05 & 26.65 \\
\hline \multirow{3}{*}{ Zr25Ti } & $20^{\circ}$ & 465.1 & 459.4 & 185.2 & 182.9 & 530.9 & 1.02 & 3.85 & 19.8 \\
\hline & $45^{\circ}$ & 465.2 & 459.5 & 185.4 & 182.9 & 530.9 & 1.45 & 4.25 & 20.41 \\
\hline & $80^{\circ}$ & - & 459.6 & 185.2 & 182.9 & & & & \\
\hline \multirow{3}{*}{ Zr45Ti } & $20^{\circ}$ & 465.3 & 459.6 & 185.7 & 183.3 & 531.2 & 1.93 & 2.77 & 18.32 \\
\hline & $45^{\circ}$ & 465.2 & 459.4 & 185.5 & 183.1 & 531.0 & 2.57 & 3.07 & 20.79 \\
\hline & $80^{\circ}$ & 465.3 & 459.5 & 185.7 & 183.3 & 531.2 & 1.41 & 1.76 & 15.82 \\
\hline
\end{tabular}


Table 2. Electrochemical parameters determined from the potentiodynamic polarization curves measured for the thermally-oxidized ZrTi samples in acidified Fusayama solution $(\mathrm{pH}=3)$ containing fluoride additions at $37^{\circ} \mathrm{C}$.

\begin{tabular}{|c|c|c|c|}
\hline Sample & $E_{\text {corr }} / V_{\text {SCE }}$ & $j_{\text {corr }} / \mu \mathrm{A} \mathbf{c m}^{-2}$ & $\boldsymbol{j}_{\text {pass }}{ }^{*} / \boldsymbol{\mu} \mathbf{A ~} \mathbf{c m}^{-2}$ \\
\hline \multicolumn{4}{|c|}{ Artificial saliva $+0.2 w t . \% \mathrm{NaF}$} \\
\hline Zr5Ti & $-0.051(0.009)$ & $0.9(0.14)$ & $4.5(0.53)$ \\
\hline Zr25Ti & $-0.244(0.028)$ & $2.8(0.25)$ & $4.8(0.40)$ \\
\hline Zr45Ti & $-0.119(0.023)$ & $1.4(0 . .30)$ & $5.6(0.35)$ \\
\hline \multicolumn{4}{|c|}{ Artificial saliva $+0.5 w t . \% \mathrm{NaF}$} \\
\hline Zr5Ti & $-0.226(0.015)$ & $1.1(0.17)$ & $10.9(0.42)$ \\
\hline Zr25Ti & $-0.338(0.019)$ & $4.1(0.29)$ & $10.6(0.50)$ \\
\hline Zr45Ti & $-0.291(0.035)$ & $2.1(0.35)$ & $6.1(0.16)$ \\
\hline \multicolumn{4}{|c|}{ Artificial saliva +1 wt.\% NaF } \\
\hline Zr5Ti & $-0.446(0.025)$ & $1.5(0.30)$ & $14.9(0.71)$ \\
\hline Zr25Ti & $-0.721(0.032)$ & $6.1(0.40)$ & $19.3(2.46)$ \\
\hline Zr45Ti & $-0.523(0.023)$ & $3.6(0.52)$ & $11.8(1.80)$ \\
\hline
\end{tabular}

Note: standard deviations are given in parentheses.

*Values determined at $+0.40 \mathrm{VSCE}$ 
Table 3. Parameters of the equivalent circuit for thermally-oxidized ZrTi alloys in acidified Fusayama solution $(\mathrm{pH}=3)$ containing fluoride additions at $37^{\circ} \mathrm{C}$. AC polarization was applied around their corresponding open circuit potential values in the electrolytes.

\begin{tabular}{|c|c|c|c|c|c|c|c|c|}
\hline Sample & $\begin{array}{l}\text { Concentration } \\
\text { of } \mathrm{NaF} / \mathrm{wt} . \%\end{array}$ & $\begin{array}{c}10^{5} Q_{1} / \\
S \mathrm{~cm}^{-2} \mathrm{~s}^{\mathrm{n}}\end{array}$ & $n_{1}$ & $\begin{array}{c}R_{1} / \\
\mathbf{k} \Omega \mathbf{c m}^{2}\end{array}$ & $\begin{array}{c}10^{6} Q_{2} / \\
S \mathrm{~cm}^{-2} \mathrm{~s}^{\mathrm{n}}\end{array}$ & $n_{2}$ & $\begin{array}{c}R_{2} / \\
\mathrm{M} \Omega \mathbf{c m}^{2}\end{array}$ & $10^{5} \chi^{2}$ \\
\hline \multirow[t]{3}{*}{ Zr5Ti } & 0.2 & 2.5 & 0.81 & 4.3 & 8.5 & 0.83 & 2.1 & $5.4(0.37)$ \\
\hline & 0.5 & 2.6 & 0.80 & 3.9 & 8.9 & 0.82 & 1.5 & $38(5.1)$ \\
\hline & 1 & 2.6 & 0.80 & 3.5 & 9.1 & 0.81 & 1.2 & $31(2.7)$ \\
\hline \multirow[t]{3}{*}{ Zr25Ti } & 0.2 & 3.4 & 0.79 & 2.1 & 11.2 & 0.80 & 0.6 & $4.1(0.40)$ \\
\hline & 0.5 & 3.1 & 0.79 & 1.9 & 11.4 & 0.80 & 0.5 & $7.7(0.44)$ \\
\hline & 1 & 3.2 & 0.78 & 1.5 & 11.8 & 0.79 & 0.3 & 9.1 (1.10) \\
\hline \multirow[t]{3}{*}{ Zr45Ti } & 0.2 & 2.5 & 0.80 & 4.1 & 8.7 & 0.82 & 1.9 & $3.2(0.41)$ \\
\hline & 0.5 & 2.6 & 0.80 & 3.7 & 8.9 & 0.81 & 1.4 & 6.8 (1.18) \\
\hline & 1 & 2.9 & 0.79 & 3.7 & 9.7 & 0.80 & 0.5 & $13(3.6)$ \\
\hline
\end{tabular}

Note: standard deviations are given in parentheses. 
Table 4. Film thickness estimated from EIS results measured for oxidized ZrTi alloys in acidified Fusayama solution $(\mathrm{pH}=3)$ containing fluoride additions at $37^{\circ} \mathrm{C}$.

\begin{tabular}{|c|c|c|c|}
\hline Sample & $\begin{array}{c}\text { Concentration } \\
\text { of } \mathbf{N a F} / \mathbf{w t} . \%\end{array}$ & $\begin{array}{c}\text { Capacitance of the inner } \\
\text { oxide layer } / \boldsymbol{\mu} \mathbf{F} \mathbf{~ c m}^{-\mathbf{2}}\end{array}$ & $\begin{array}{c}\text { Film thickness of the } \\
\text { inner oxide layer } / \mathbf{~ m m}\end{array}$ \\
\hline \multirow{2}{*}{ Zr5Ti } & 0.2 & 15.3 & 1.39 \\
\cline { 2 - 4 } & 0.5 & 15.7 & 1.36 \\
\cline { 2 - 4 } & 1 & 15.9 & 1.34 \\
\hline Zr25Ti & 0.2 & 18.0 & 1.19 \\
\cline { 2 - 4 } & 0.5 & 17.6 & 1.21 \\
\cline { 2 - 4 } & 1 & 16.5 & 1.29 \\
\hline Zr45Ti & 0.2 & 16.1 & 1.32 \\
\cline { 2 - 4 } & 0.5 & 16.0 & 1.33 \\
\cline { 2 - 4 } & 1 & 14.4 & 1.49 \\
\hline
\end{tabular}

Table 5. Parameters of the equivalent circuit for as cast ZrTi alloys in acidified Fusayama solution (pH = 3) containing $0.5 \mathrm{wt} . \% \mathrm{NaF}$ at $37^{\circ} \mathrm{C}$. AC polarization was applied around their corresponding open circuit potential values in the electrolyte.

\begin{tabular}{|c|c|c|c|c|c|}
\hline Sample & $\begin{array}{l}10^{5} Q_{1} / \\
\mathrm{S} \mathrm{cm}^{-2} \mathrm{~s}^{\mathrm{n}}\end{array}$ & $n_{1}$ & $\begin{array}{c}R_{1} / \\
\mathbf{k} \Omega \mathbf{c m}^{2}\end{array}$ & $\begin{array}{c}L / \\
\mathbf{H ~ c m}^{-2}\end{array}$ & $\begin{array}{c}R_{2} / \\
\Omega \mathbf{c m}^{2}\end{array}$ \\
\hline Zr5Ti & 3.2 & 0.84 & 0.8 & 325 & 82 \\
\hline Zr25Ti & 3.3 & 0.83 & 0.6 & 342 & 77 \\
\hline Zr45Ti & 2.9 & 0.84 & 0.9 & 289 & 89 \\
\hline
\end{tabular}



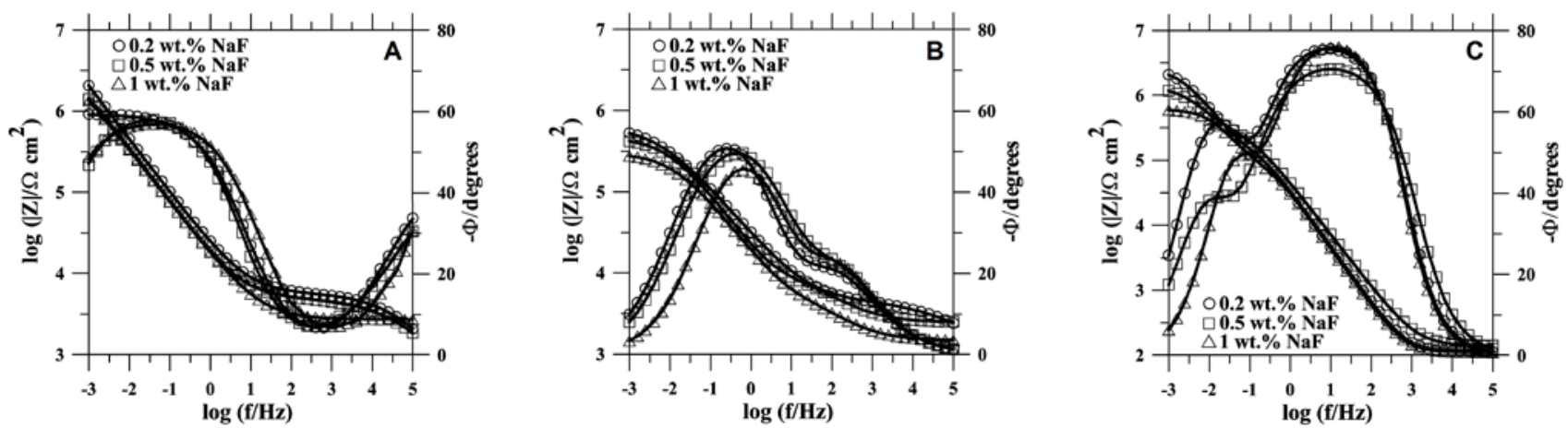

Figure 1. Measured impedance spectra for thermally-oxidized ZrTi alloy samples recorded at their open circuit potentials during exposure to aerated acidified artificial saliva $(\mathrm{pH}=3)$ containing different $\mathrm{NaF}$ concentrations as indicated in the plots. Materials: (A) Zr5Ti, (B) Zr25Ti, and (C) Zr45Ti.
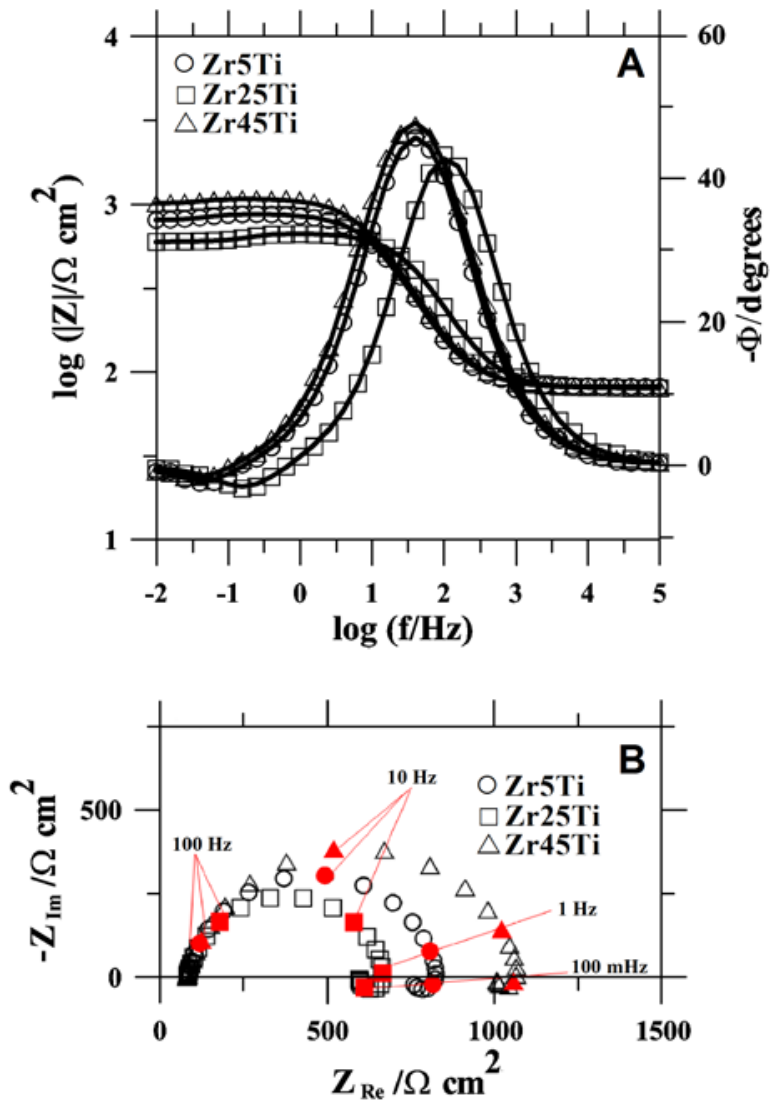

Figure 2. Measured impedance spectra for as cast (untreated) ZrTi alloy samples recorded at their open circuit potentials during exposure to aerated acidified artificial saliva $(\mathrm{pH}=3)$ containing $0.5 \mathrm{wt} \% \mathrm{NaF}$. (A) Bode, and (B) Nyquist representations. 

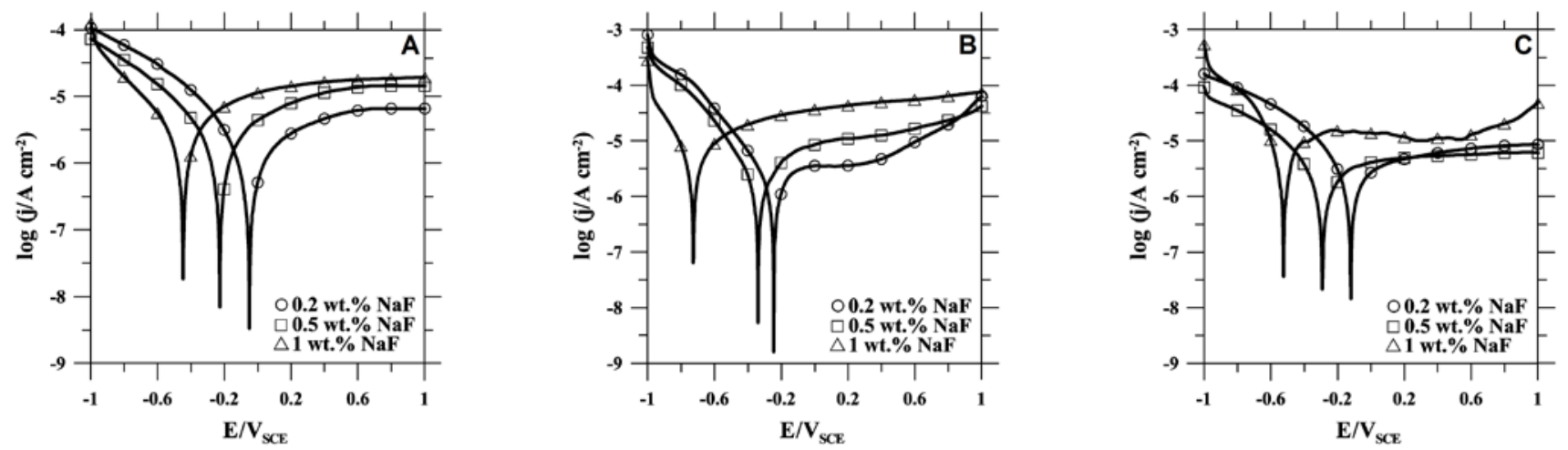

Figure 3. Linear potentiodynamic polarization curves of the thermally-oxidized ZrTi alloy samples recorded at their open circuit potentials during exposure to aerated acidified artificial saliva $(\mathrm{pH}=3)$ containing different NaF concentrations as indicated in the plots. Materials: (A) Zr5Ti, (B) Zr25Ti, and (C) Zr45Ti. Scan rate: $1 \mathrm{mV} \mathrm{s}^{-1}$.
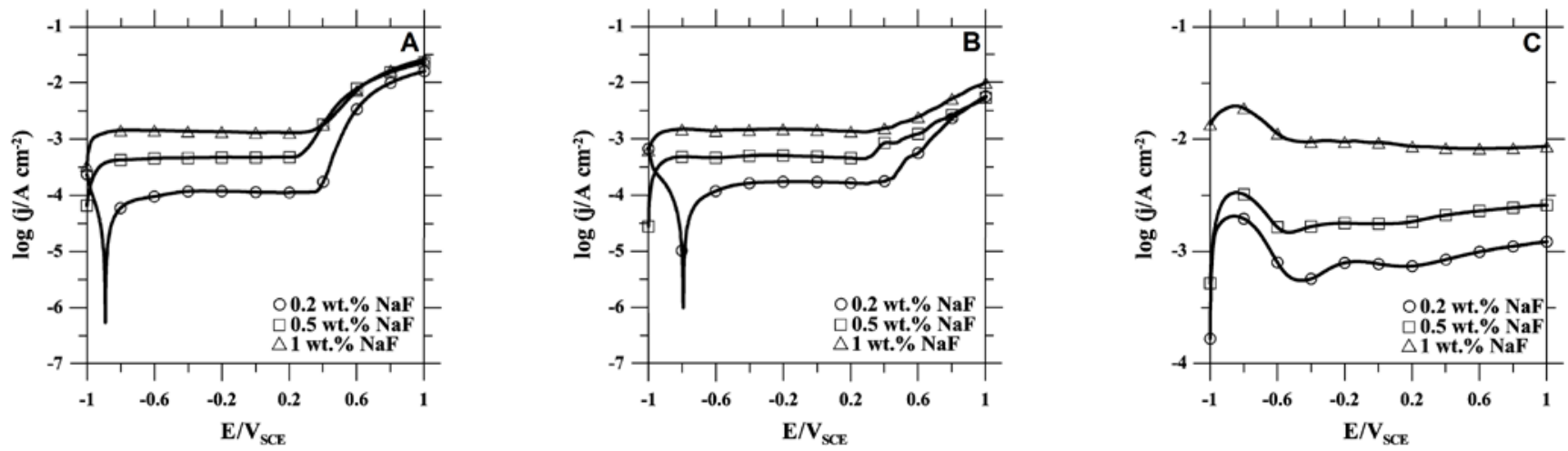

Figure 4. Linear potentiodynamic polarization curves of the cast ZrTi alloy samples recorded at their open circuit potentials during exposure to aerated acidified artificial saliva $(\mathrm{pH}=3)$ containing different NaF concentrations as indicated in the plots. Materials: (A) Zr5Ti, (B) Zr25Ti, and (C) Zr45Ti. Scan rate: $1 \mathrm{mV} \mathrm{s}^{-1}$. 

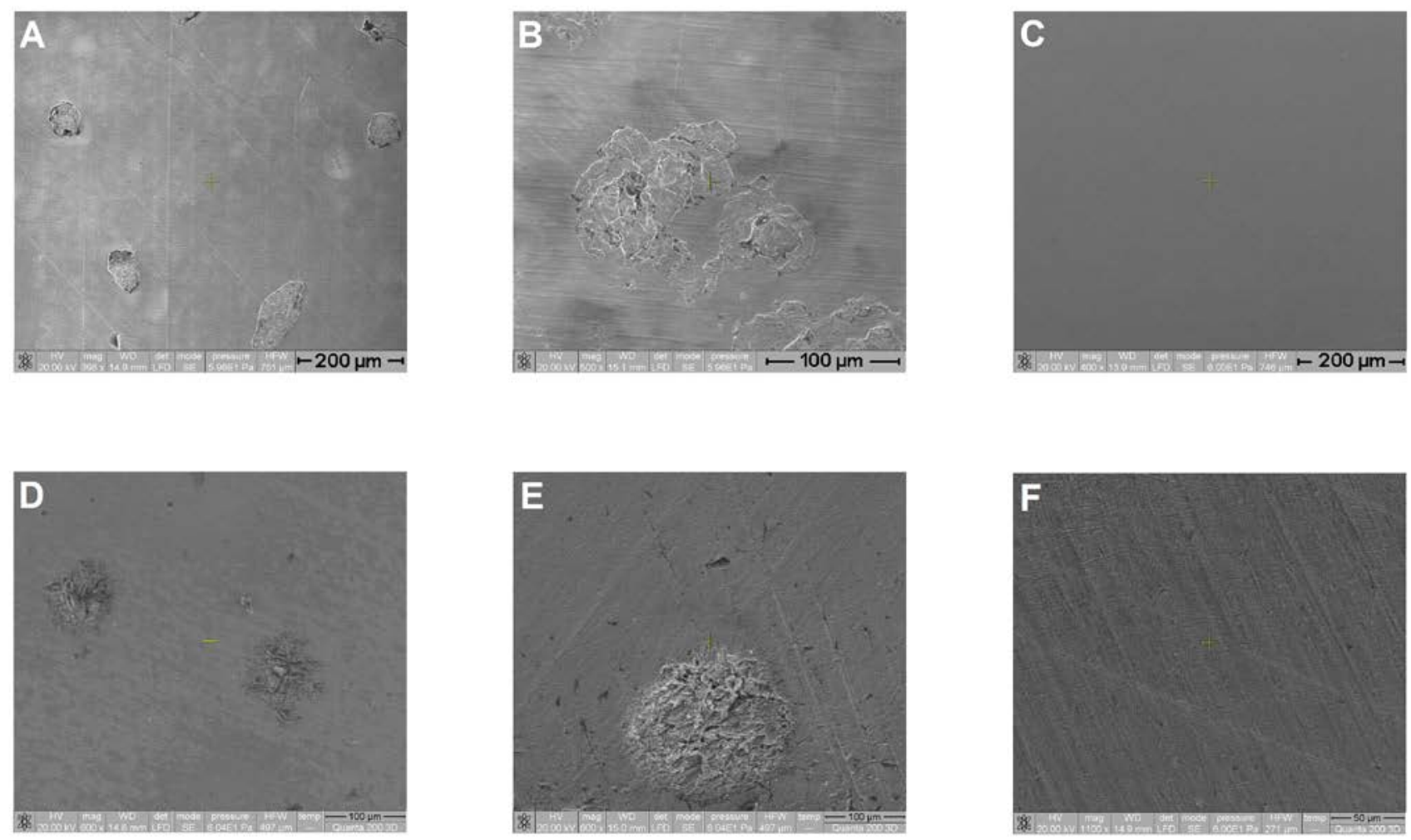

Figure 5. SEM images of (A-C) thermally-oxidized and (D-F) cast ZrTi alloys retrieved from acidified artificial saliva with $1 \mathrm{wt} \% \mathrm{NaF}$ after recording the potentiodynamic polarization curves in Figure 5. Materials: (A,D) Zr5Ti, (B,E) Zr25Ti, and (C,F) Zr45Ti.
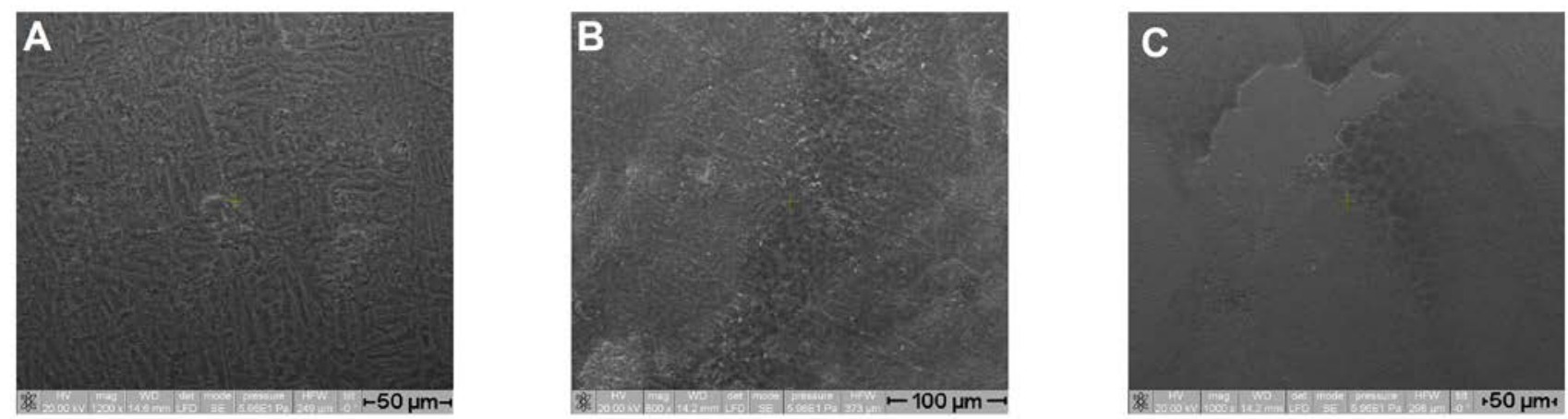

Figure 6. SEM images of as cast ZrTi alloys retrieved from acidified artificial saliva with $0.5 \mathrm{wt} . \% \mathrm{NaF}$ after 1 hour immersion time at their corresponding open circuit potential values $\left(E_{\text {corr }}\right)$. 


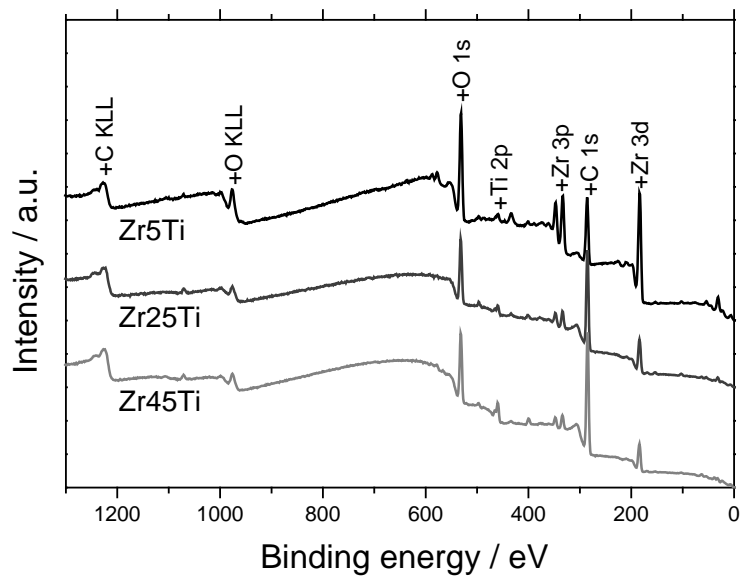

Figure 7. XPS survey spectra recorded at the surface of thermally-oxidized ZrTi alloys in air at $500{ }^{\circ} \mathrm{C}$ for 2 hours. The spectra have been shifted along $y$-axis for the sake of clarity.
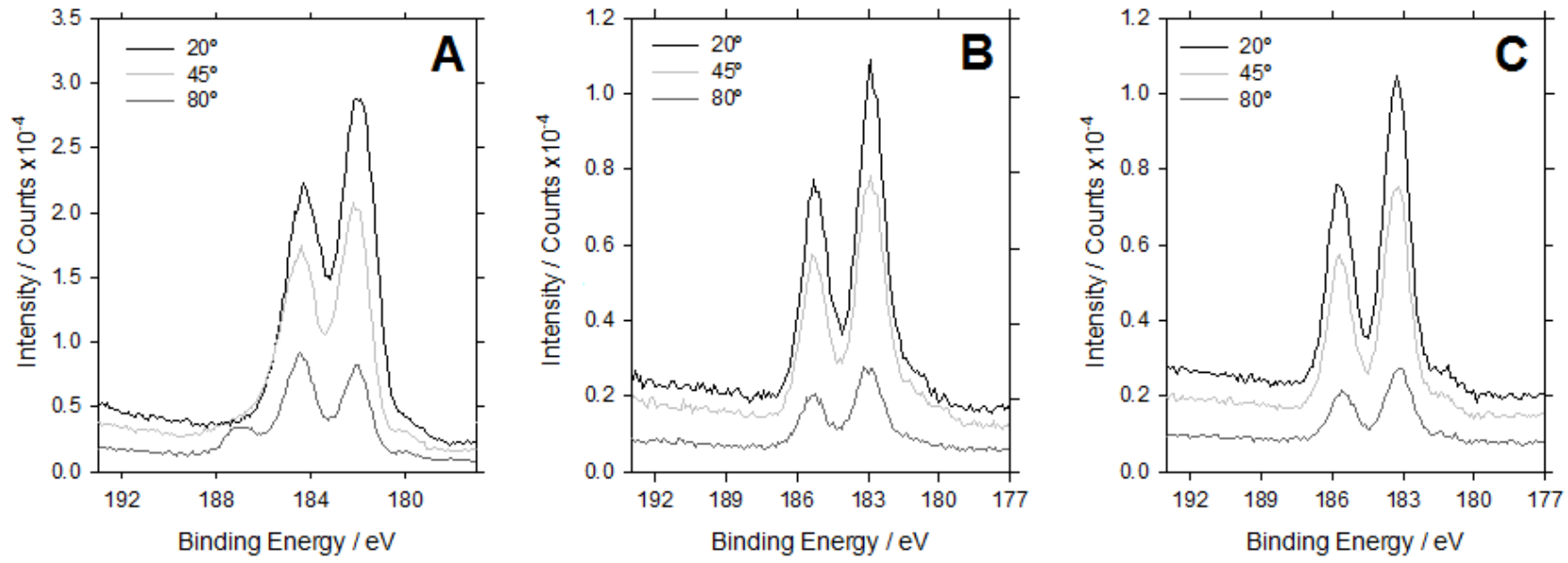

Figure 8. XPS zirconium Zr 3d spectra recorded at the surface of the thermally-oxidized ZrTi alloys at take-off angles 20, 45 and 80. Materials: (A) Zr5Ti, (B) Zr25Ti, and (C) Zr45Ti. 

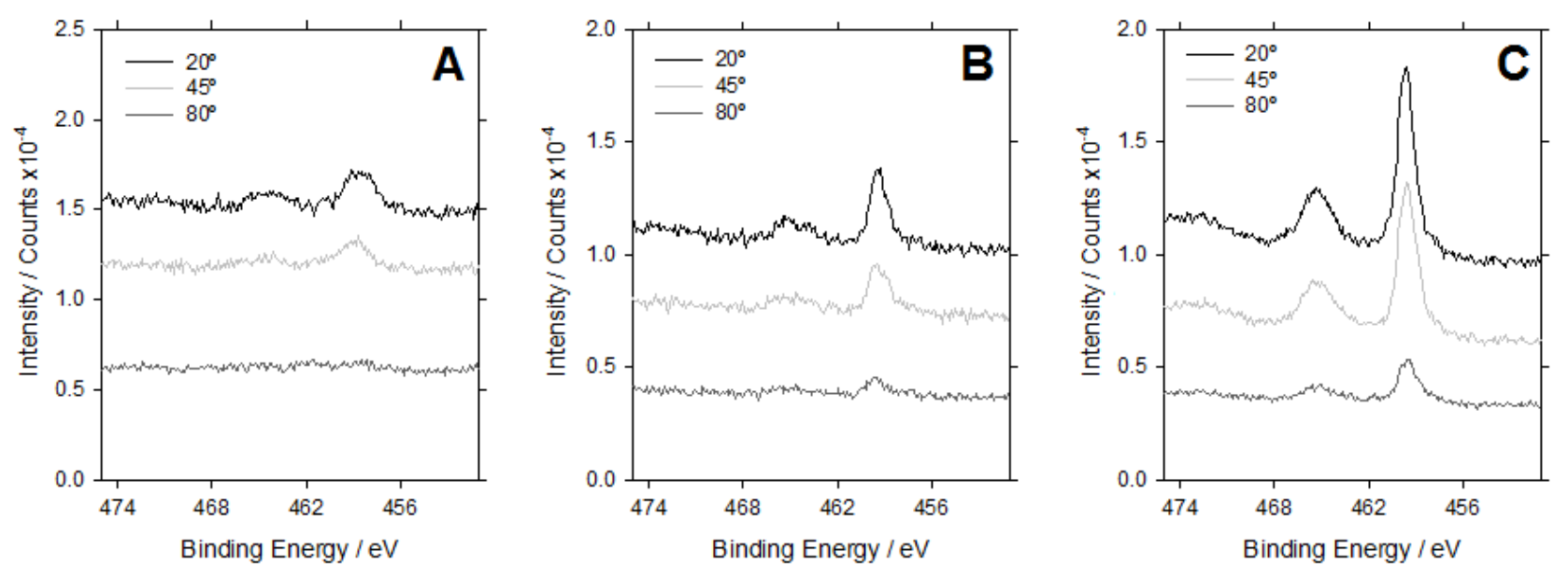

Figure 9. XPS titanium Ti 2p spectra recorded at the surface of the thermally-oxidized ZrTi alloys at take-off angles 20, 45 and 80'. Materials: (A) Zr5Ti, (B) Zr25Ti, and (C) Zr45Ti.

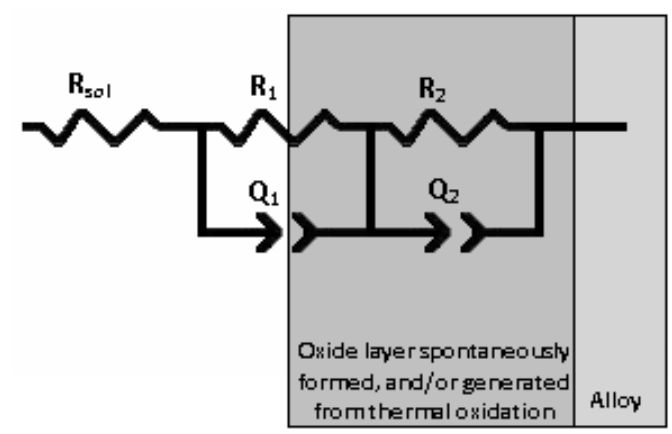

(A)

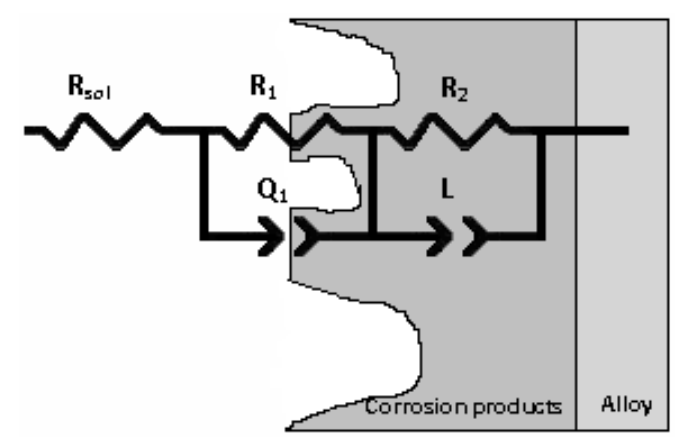

(B)

Figure 10. Equivalent circuits (EC) used to fit the impedance data: (A) two-layer model of an unsealed porous surface film [46]; and (B) one-layer model accounting relaxation processes corresponding to the precipitation of corrosion products [63]. 